Computer Applications: An International Journal (CAIJ), Vol.3, No.2, May 2016

\title{
A SURVEY ON UNDULATORY MOTION BASED ROBOTIC FISH DESIGN
}

\author{
S.Swarnamugi ${ }^{1}$, S.Raja Mohamed $^{2}$, Dr.P.Raviraj ${ }^{3}$ \\ ${ }^{1}$ PG scholar, Dept. of CSE,KIT, Coimbatore, Tamilnadu, India. \\ ${ }^{2}$ Associate Professor, Dept. of CSE, KIT, Coimbatore, Tamilnadu, India. \\ ${ }^{3}$ Professor, Dept. of CSE, KIT, Coimbatore, Tamilnadu, India.
}

\begin{abstract}
A BSTRACT
Robotic fish design (Biomimetic) is an upcoming research area in which undulation motion has its own set of parameters to decide its efficiency. To analyse its swimming efficiency several existing robotic models using undulation motion have been thoroughly studied and few critical parameters such as fin size, shape, flexibility of material, fin flapping rate etc., have been identified. After simulating the above critical parameters using a MATLAB based CFD tool, mainly to design prototypes for research purpose which concentrates on optimizing its swimming efficiency. Several combinations of critical parameters are discussed for robotic fish prototype design by identifying critical parameters and maximizing the swimming efficiency of robotic fish based on the above properties. The fin models have been tested using Matlab based CFD tool through simulation and the swimming speed, direction have also been tested for various models. An improved benchmark for designing robotic fish model is proposed in order to simplify selection of components, architecture, and cost involve.
\end{abstract}

\section{Keywords}

Computational Fluid Dynamics (CFD), Body and/or Caudal Fin (BCF), Median and/or Paired Fin (MPF), Biomimetic

\section{INTRODUCTION}

Fish fins are a large amount of distinctive characteristic of a fish, collection of thin backbone protrude from the body with skin casing and fusing them. Caudal fins contain no straight connection with the backbone and are supported by strength only. Fins positioned in dissimilar spaces on the fish provide diverse purposes such as moving frontward, rotating, keeping an upright location or stopping. Fish swim also by Body and/or Caudal Fin (BCF) movements or using Median and/or Paired Fin(MPF) propulsion. Undulation and Oscillation are the two movements of the Body and/or Caudal Fin. In this paper we have described about Undulation movement. Undulation is the movement in which the fish uses its half of the body to swim. The undulatory motion adapted by fishes are given below

\subsection{Eel Fish}

Eels are extended fish, range in duration from $5 \mathrm{~cm}$. Adults choice in weight starting $30 \mathrm{~g}$ well over $25 \mathrm{~kg}$. They acquire no pelvic fins, and a lot of species also not have pectoral fins. Anal and 
Dorsal fins are combined with the caudal fin. Eels swim by generate body effect which move the span of their bodies. They can swim backward direction by overturn the way of the wave ${ }^{[1]}$.

\subsection{Nurse Shark}

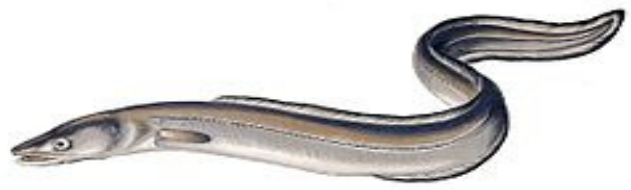

Figure1. Eel Fish ${ }^{[11]}$

Nurse sharks can achieve a length of $3.08 \mathrm{~m}$. Nurse shark has two smoothed dorsal fins, smoothed pectoral fins, an extended caudal fin, and a large skull. And these sharks are brownish color. Highest adult length recognized by dependable reports is $3.08 \mathrm{~m}$; previous information of lengths up to $4.5 \mathrm{~m}$ and matching weights of up to $330 \mathrm{~kg}$ are possible to have been overstated.

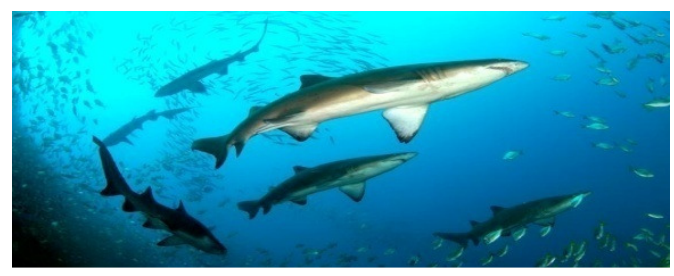

\subsection{Tuna Fish}

Figure2. Nurse Shark ${ }^{[11]}$

Tunas are extended and streamlined fishes; they contain a smoothed body that narrow to a slim tail base and a divided or crescent-shaped tail. tunas are exclusive among fishes in their capability to preserve the heat of their bodies higher than that of the nearby water, frequently between 5 and $12^{\circ} \mathrm{C}$ above ambient water heat. A few muscles may still be awake to $21^{\circ} \mathrm{C}$ higher than the nearby water.

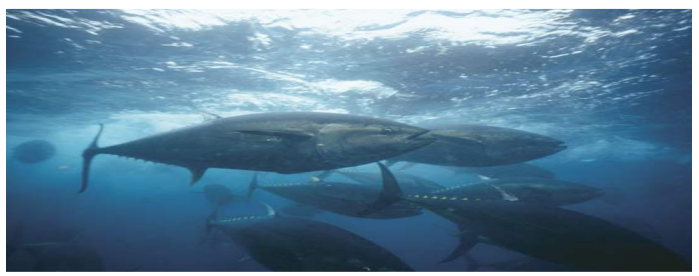

Figure3. Tuna Fish ${ }^{[11]}$

\subsection{Bamboo shark Fish}

A carpet shark by means of an adult dimension that approach is one meter in length. Typically night-time species is risk-free to human beings. It can raise up to 93 centimeters long. The teeth are not muscularly differentiated. Every tooth has a medial cusp with 26 to 35 teeth on the upper jaw and 21 to 32 teeth on the lower jaw. 
Computer Applications: An International Journal (CAIJ), Vol.3, No.1, May 2016

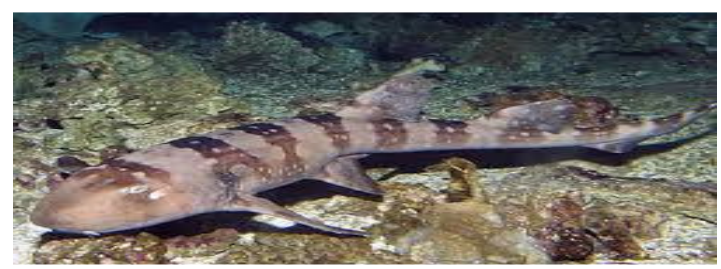

Figure4. Bamboo Shark Fish ${ }^{[11]}$

\section{BACKGROUND}

Undulatory locomotion is termed Body-Caudal Fin (BCF) swimming on the origin of the body structures used ${ }^{[2]}$. An undulatory swimming mode thrust is formed by wave like group of the propulsive arrangement. Swimming locomotion has been classified into two general categories Periodic swimming and Transient swimming. Periodic swimming is engaged by fish to cover up comparatively large distance at a more or less regular speed. Transient Movement last millisecond and are usually used for catching prey or predator avoidance.

To increase the efficiency and speed of the robotic fish, change the Caudal fins by using different fin types. The different types of fins are round, forked, indented, truncate, luncate, pointed. The undulatory based fish swimming models are Angulliform, Sub carangiform, and Thunniform ${ }^{[3][4][5]}$. Angulliform: The fish body flexes one full wave length or more. Fish body moves like sin wave, head is rigid. Carangiform: The fish body flexes less than $1 / 2$ wavelength. The $1 / 3$ of body muscle mass is used to generate propulsion. Sub Carangiform: Common swimming modes for many familiar freshwater fishes. Between $1 / 2$ and $2 / 3$ of body muscle mass is used to generate undulating waves down the body. Thunniform: Thrust is generated by the caudal fin, which is large strong and forked.

\section{Robotic Fish Models}

Filose Robot Fish: The FILOSE researchers have produced a sequence of lab-based robotic fishes based on the rainbow trout, that include their own man-made lateral lines. These lines integrate tiny cantilevered piezoelectric sensors that bend in reply to flow - the stronger the present, the additional they bend, and the better electrical signal that they generate. Fish that go frontward by create undulations in back part of the body while the front of the body remains roughly inflexible.

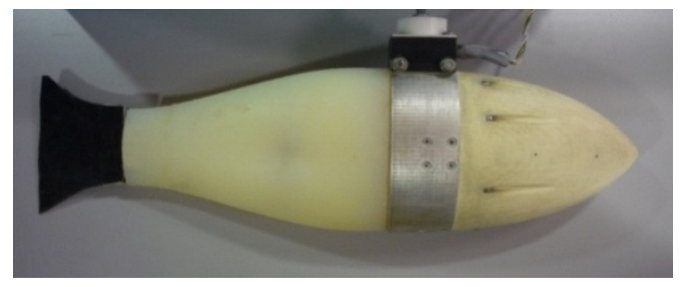

Figure5. FILOSE Robot Fish ${ }^{[12]}$

Robo Tuna: The RoboTuna is a robotic fish project concerning a sequence of robotic fish considered and built by a group of scientists at the Massachusetts Institute of Technology ${ }^{[11]}$. It can reach speed up to $50 \mathrm{mph}$. 


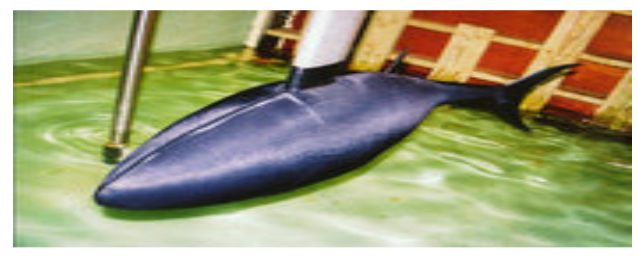

Figure6. Robo Tuna ${ }^{[13]}$

The ability of aquatic animals to sense their surroundings through force and speed sensing is best exemplify by the blind cave fish, which dart through messy cave environment in absolute darkness, and the harbor seal, which detect the minute fluctuations in the arouse of prey up to $30 \mathrm{~s}$ after it has accepted. continued existence has dictate the improvement of such hydrodynamic sensing, which is absolutely absent from engineered structures. Their force and maneuverable motions are produced by the last half of their body. It is noticed that we are not taking into consideration non-carangiform types of fish. Since they need a totally different model and control method are being investigated.

\section{Existing Work}

Table 1. List of papers referred on designing fish models.

\begin{tabular}{|c|c|c|}
\hline CASE NO & TITLE & AUTHORS \\
\hline CASE 1 & $\begin{array}{l}\text { Design, Fabrication and Hydrodynamic } \\
\text { Analysis of a Biomimetic Robot Fish }\end{array}$ & $\begin{array}{l}\text { DonyaMohammadshahi, } \\
\text { AghilYousefi-koma, } \\
\text { ShahnazBahmanyar, Hassan } \\
\text { Ghassemi, Hessam Maleki }\end{array}$ \\
\hline CASE 2 & $\begin{array}{l}\text { Backward swimming gaits for a carangiform } \\
\text { robotic fish }\end{array}$ & $\begin{array}{l}\text { Chao Zhou ,Zhiqiang Cao, } \\
\text { Zeng-Guang Hou, } \\
\text { Shuo Wang,Min Tan }\end{array}$ \\
\hline CASE 3 & $\begin{array}{l}\text { Hydrodynamic Modeling of an Undulating } \\
\text { Fin for Robotic Fish } \\
\text { Design }\end{array}$ & $\begin{array}{l}\text { Fangfang Liu, Can-Jun Yang, } \\
\text { and Kok-Meng Lee }\end{array}$ \\
\hline CASE 4 & $\begin{array}{l}\text { 3D Hydrodynamic Analysis of } \\
\text { a Biomimetic Robot Fish }\end{array}$ & $\begin{array}{l}\text { Zhenying Guan, Weimin Gao, } \\
\text { Nong Gu, Saeid Nahavandi }\end{array}$ \\
\hline CASE 5 & $\begin{array}{l}\text { Design of } 3 d \text { swim patterns for autonomous } \\
\text { robotic fish }\end{array}$ & $\begin{array}{l}\text { Huosheng } \mathrm{Hu} \text {, Jindong Liu, Ian } \\
\text { Dukes and George Francis }\end{array}$ \\
\hline CASE 6 & 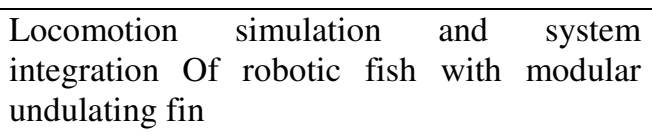 & K. H. Low \\
\hline CASE 7 & $\begin{array}{l}\text { Hydrodynamic Performance of } \\
\text { an Undulatory Robot: Functional Roles of } \\
\text { the Body and Caudal Fin Locomotion }\end{array}$ & $\begin{array}{l}\text { Li Wen, Jianhong Liang, Qi } \\
\text { Shen, Lei Bao and Qian Zhang }\end{array}$ \\
\hline CASE 8 & $\begin{array}{l}\text { Design, Implementation and Control of a } \\
\text { Fish Robot with Undulating Fins }\end{array}$ & $\begin{array}{l}\text { MohsenSiahmansouri, } \\
\text { AhmadGhanbari and Mir } \\
\text { MasoudSeyyedFakhrabadi }\end{array}$ \\
\hline CASE 9 & $\begin{array}{l}\text { A Dynamic Model for Robotic Fish with } \\
\text { Flexible Pectoral Fins }\end{array}$ & $\begin{array}{l}\text { Sanaz Bazaz Behbahani, } \\
\text { Jianxun Wang, and Xiaobo Tan }\end{array}$ \\
\hline
\end{tabular}


Computer Applications: An International Journal (CAIJ), Vol.3, No.1, May 2016

\subsection{Case wise Analysis}

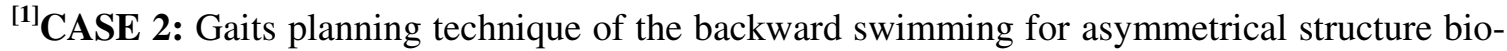
inspired robotic fish. Based on the difference between the anguilliform method and carangiform method swimming, a technique for searching gaits of toward the back swimming was considered to plan the motion of the residential carangiform robotic fish.The body cover of European eel's backward swimming was mimicked according to the unreservedly swimming form, which was planned to analyze the propulsion formed by the undulation of the multi-link tail. The giants searching algorithm is adopt to find appropriate giants. The prototype of carangiform robotic fish and a shift model of free swimming were inducted besides to search backward swimming gaits. The simulation and experiment were carry out to show the gaits searching method for the bioinspired carangiform robotic fish.

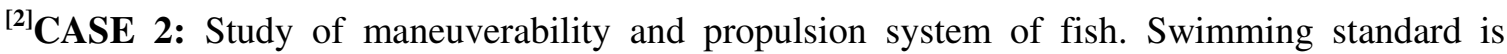
achieved from Carangiform swimming method. This is the swimming method of fish that make use of their tail and peduncle used for propulsion. In the procedure of optimizing the presentation parameters of ADCSL robot fish, a 2D representation of robot fish is measured. In order to estimate hydrodynamic forces, Computational Fluid Dynamic (CFD) technique was used besides analysis results. The Computational Fluid Dynamic, CFD, testing performance parameter of robot fish are evaluate and enhanced by changing unlike design parameters. It provides useful results to optimize routine parameters in the method of propose and fabrication. It is well identified that the tuna swims

with elevated speed and elevated efficiency, the point accelerates in a flash as well as the eel could swims skill totally into narrow holes.

${ }^{[3]}$ CASE 3: Design of a robotic fish is been developed for trial analysis and for validating computational hydrodynamic model of an undulating fin. Computational Fluid Dynamic (CFD) method is being used. The force and speed distributions substitute on the undulating fin have been numerically solved using the finite volume method $(\mathrm{FVM})^{[3]}$, which provides the source to calculate the forces performing on the undulating fin.The validation basis to examine the outcome of fluid flow around the automatic fin on thrust performance. The computational representation has been experimentally validated by comparing the computed thrust coefficient. A comparatively absolute computational replica relating the hydrodynamics of an undulating fin is given. Objective values of the numerical and kinematic parameters used in the calculation are based on a sample flexible-fin mechanism so that geometric solutions can be validated experimentally.

${ }^{[4]}$ CASE 4: Study is to obtain relative information about hydrodynamic properties of those strategy to develop the plan, remote control and elasticity of the underwater robot fish. Flowing and user-defined function (UDF) is used to describe the progress of the robot fish and the mimic of robotic fish swimming dynamic mesh is used. A computational fluid dynamic copy was construct for a biomimetic robot fish. A lot of hydrodynamic property, such as the exert pressure and the energy of the fish, have been obtain. The CFD simulation provides the in sequence of the flow of water approximately the robot fish and the force distribution, used for the optimization of robot fish and the enhancement of the plan and production of the robot fish.

${ }^{[5]}$ CASE 5: Sensor based control of self-directed robotic fish that can swim in a 3D shapeless environment, based on the remarks of fish swim behaviors. The robotic fish has a tail with four 
Computer Applications: An International Journal (CAIJ), Vol.3, No.1, May 2016

degrees of freedom (DOF) and is guarded by 4 aboard systems and over 10 surrounded sensors. The tuna swim with elevated speed and elevated efficiency, the pike accelerates in a burst and the eel can swim capably into thin holes. A number of fish swim model have been built-up to recognize the fish-like swimming progress as a carangiform fish. Periodic swimming is characterised by a repeated recurrence of the propulsive movement for a elongated distance at a accidental speed. Unsteady swimming includes fast start, jagged turn, burst and brake. Temporary movements last seconds and are usually for catching prey or avoid predator.

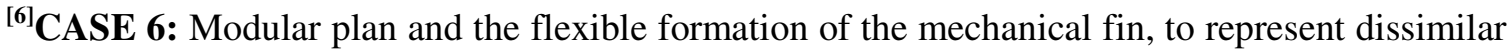
types of fin and to build a variety of biomimetic robots of fish swimming by fin undulation. Propulsors and vehicles that follow the movement of fish have been residential for technical appliance, using state-of-the-art technology, robotics and an thoughtful of how fish swim. The fin-based thrust system perform glowing for equally high-speed cruising as well as high maneuverability in fish, making them good quality models for propulsors of underwater vehicle. Further detailed study on fin locomotion and hydrodynamics must be completed in order to render proper and efficient control achievement on the present robot.

${ }^{[7]}$ CASE 7: Hydrodynamic was calculated as a purpose of the principal kinetic parameter of the undulatory body and caudal fin representation in a self propelled position, under which the point averaged is considered and the axial net force be converted into zero.Thrust efficiency was predictable from two dimensional Digital Particle Image Velocimetry (DPIV) dimensions in the straight and mid-caudal fin plane. Concurrently calculate the power, consumption, self propulsion velocity and wake structure of a robotic representation. To compute the flow field and then analyse the thrust energy of the swimming robotic fish using a two dimensional advance, the laser sheet plane of the DPIV scheme must be set to pass during the midline of the Homocercal caudal fin of the mechanical fish.

${ }^{[8]}$ CASE 8: This paper describe about the plan of the propulsion structure and depth control of a robotic fish. This propulsive force can be familiar and focussed for fish robot manoeuvre by a automatic system with two servomotors. These servomotors control the path and depth of swimming. At last, wireless remote control scheme for the robot was considered and formed. The scheme was capable to control the robotic fish from out of the pool and up to 150 meter distance. The investigating factor causative to the propulsive force and effectiveness of undulating fins for different swimming modes. Manage and manoeuvre of the robotic fish stimulated by knife fish is much easier due to manage of presently one force direction.

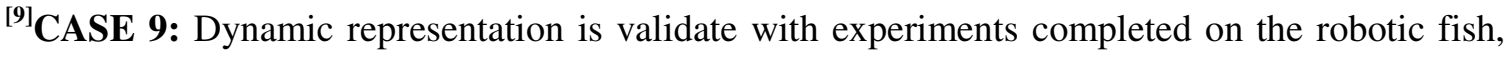
where the replica prediction of forward swimming speed and stable rotating periods and radii are initiate to match closely the tentative measurements when the pectoral fins are actuate at different frequencies. The hydrodynamic energy on each selection is calculated based on the blade element theory. A mechanical fish has been prototyped, 3D-printed body and a couple of servo-actuated elastic pectoral fins. A non-CFD active model that accommodates pectoral fin elasticity will be active in the plan and control of such robots. The energetic replica for a robotic fish activate with a pair of flexible pectoral fins. 
Computer Applications: An International Journal (CAIJ), Vol.3, No.1, May 2016

Table 2. Comparison Table

\begin{tabular}{|c|c|c|c|c|c|c|}
\hline S.No & $\begin{array}{l}\text { Body } \\
\text { Length/ } \\
\text { Weight }\end{array}$ & Sensor(s) & Pressure & Actuator(s) & $\begin{array}{l}\text { Hardware/ } \\
\text { Software }\end{array}$ & Comments \\
\hline 1 & $\begin{array}{l}0.80 \mathrm{~m} \text { in } \\
\text { length }\end{array}$ & - & $\begin{array}{l}\text { semi- } \\
\text { implicit } \\
\text { method is } \\
\text { valid for } \\
\text { small time } \\
\text { steps used } \\
\text { in the } \\
\text { simulation } \\
\text {. }\end{array}$ & $\begin{array}{l}\text { DC-motor } \\
\text { actuated } \\
\text { crank-slider } \\
\text { mechanisms, } \\
\text { The swing } \\
\text { tail controls } \\
\text { the left/right } \\
\text { turning } \\
\text { movement of } \\
\text { the fish with } \\
\text { a servomotor. }\end{array}$ & $\begin{array}{l}\text { Mechanical } \\
\text { fin, swing tail, } \\
\text { and gravity } \\
\text { allocation } \\
\text { module. }\end{array}$ & $\begin{array}{l}\text { For simulating the } \\
\text { fluid } \\
\text { flow pass the } \\
\text { flexible fin within } \\
\text { an open-ended } \\
\text { rectangular } \\
\text { channel with no- } \\
\text { slip walls. }\end{array}$ \\
\hline 2 & $\begin{array}{l}\text { Fish } \\
\text { length=5 } \\
88 \mathrm{~m} \\
\text { Fish } \\
\text { weight=2 } \\
.79 \mathrm{~g}\end{array}$ & - & $\begin{array}{l}0.09 \sim 0.62 \\
\mathrm{~m} / \mathrm{s}\end{array}$ & - & $\begin{array}{l}\text { servo towing } \\
\text { system, } \\
4,000 \text { watt AC } \\
\text { motor, } \\
\text { Controller } \\
\text { Area Network } \\
\text { (CAN) bus. }\end{array}$ & - \\
\hline 3 & $\begin{array}{l}15 \quad \mathrm{~cm} \\
\text { long, } 12 \\
\mathrm{~cm} \text { high } \\
\text { and } 6.6 \\
\mathrm{~cm} \text { wide }\end{array}$ & $\begin{array}{l}\text { gyroscope, } \\
\text { accelerome } \\
\text { ter and } \\
\text { compass } \\
\text { sensor }\end{array}$ & - & $\begin{array}{l}\text { Arduino Fio } \\
\text { microcontroll } \\
\text { er board }\end{array}$ & $\begin{array}{l}\text { SolidWorks } \\
\text { software, 3D } \\
\text { printer, power } \\
\text { converter PCB }\end{array}$ & $\begin{array}{l}\text { the flexibility of } \\
\text { the pectoral fins in } \\
\text { two directions. }\end{array}$ \\
\hline 4 & - & - & $\begin{array}{l}\text { velocity is } \\
-0.049 \\
\mathrm{~m} / \mathrm{s}\end{array}$ & $\begin{array}{l}\text { 8-link, foil- } \\
\text { flapping } \\
\text { robotic } \\
\text { mechanism. }\end{array}$ & $\begin{array}{l}\text { Gaits } \\
\text { searching } \\
\text { algorithm is } \\
\text { used. }\end{array}$ & $\begin{array}{ll}\text { Kinematic } & \\
\text { characteristics } & \text { of } \\
\text { backward } & \\
\text { swimming } & \text { of } \\
\text { European eel. } & \end{array}$ \\
\hline 5 & - & $\begin{array}{l}\text { Wireless } \\
\text { control } \\
\text { system. }\end{array}$ & - & - & $\begin{array}{l}\text { Servomotors, } \\
\text { control board. }\end{array}$ & $\begin{array}{l}\text { The propulsive } \\
\text { force can be } \\
\text { studied further by } \\
\text { using unequal } \\
\text { amplitude } \\
\text { sinusoidal waves. }\end{array}$ \\
\hline 6 & $\begin{array}{l}0.62 \mathrm{~m} \text { in } \\
\text { length, } \\
0.08 \mathrm{~m} \text { in } \\
\text { width }\end{array}$ & $\begin{array}{l}\text { Several } \\
\text { infrared } \\
\text { and } \\
\text { pressure } \\
\text { sensors }\end{array}$ & $0.7 \mathrm{~s}$ & - & Servomotors & $\begin{array}{l}\text { DPIV and POD } \\
\text { used to estimate } \\
\text { hydrodynamic } \\
\text { forces. }\end{array}$ \\
\hline 7 & $\begin{array}{l}80 \mathrm{~cm} \\
56 \mathrm{~cm}\end{array}$ & $\begin{array}{l}\text { Depth and } \\
\text { pitch } \\
\text { sensor, } \\
\text { proximity } \\
\text { sensor. }\end{array}$ & - & $\begin{array}{l}\text { Futaba, Peak- } \\
\text { to peak } \\
\text { amplitude. }\end{array}$ & $\begin{array}{l}\text { Spine, } \\
\text { Servomotors, } \\
\text { Cranks, Slider. }\end{array}$ & $\begin{array}{l}\text { Arbitrary or non- } \\
\text { hormonic fin } \\
\text { waves can be } \\
\text { achieved by } \\
\text { varying the } \\
\text { rotation and phase } \\
\text { difference of the } \\
\text { servomotors. }\end{array}$ \\
\hline
\end{tabular}


Computer Applications: An International Journal (CAIJ), Vol.3, No.1, May 2016

\begin{tabular}{|c|c|c|c|c|c|c|}
\hline 8 & $60 \mathrm{~cm}$ & - & $\begin{array}{l}\text { speed of } \\
75 \mathrm{~cm} / \mathrm{s}\end{array}$ & $\begin{array}{l}\text { The } \mathrm{R} / \mathrm{C} \\
\text { receiver, } \\
\text { servo cranks, } \\
\text { and push rod } \\
\text { linkages }\end{array}$ & $\begin{array}{l}\text { Three } \\
\text { servomotors } \\
\text { (servos), } \\
\text { wireless } \\
\text { camera }\end{array}$ & $\begin{array}{l}\text { The propulsive } \\
\text { force induced by } \\
\text { the robot fish } \\
\text { provides the input } \\
\text { for stability and } \\
\text { control system. }\end{array}$ \\
\hline 9 & $52 \mathrm{~cm}$ & $\begin{array}{l}\text { Infrared } \\
\text { sensor, } 10 \\
\text { embedded } \\
\text { sensors, } 1 \\
\text { pressure } \\
\text { sensor, } 2 \\
\text { position } \\
\text { sensors, } 2 \\
\text { current } \\
\text { sensors, }\end{array}$ & - & $\begin{array}{l}3 \text { powerful } \\
\text { R/C servo } \\
\text { motors and } 2 \\
\text { DC motors }\end{array}$ & $\begin{array}{l}\text { 400Mhz } \\
\text { Gumstix Linux } \\
\text { computer, } \\
\text { servo control } \\
\text { board, ADC } \\
\text { board and } \\
\text { sensor board }\end{array}$ & $\begin{array}{l}\text { the design and } \\
\text { construction of } \\
\text { autonomous } \\
\text { robotic fish that } \\
\text { can swim in a 3D } \\
\text { unstructured } \\
\text { environment. }\end{array}$ \\
\hline
\end{tabular}

\section{Prototype Model}

A simple robotic fish model which has several segments, interconnected sections using Bio Hydrodynamic Toolbox (BHT) in Mat lab to test its computational effects while swimming ${ }^{[10]}$.

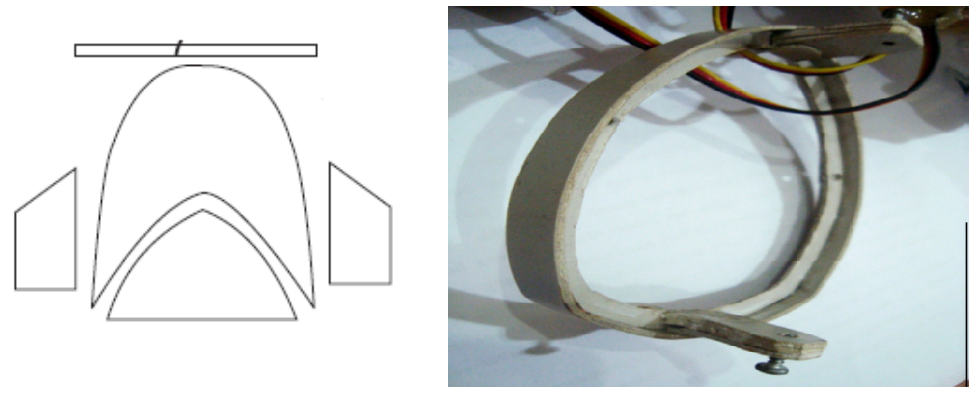

$(8)$
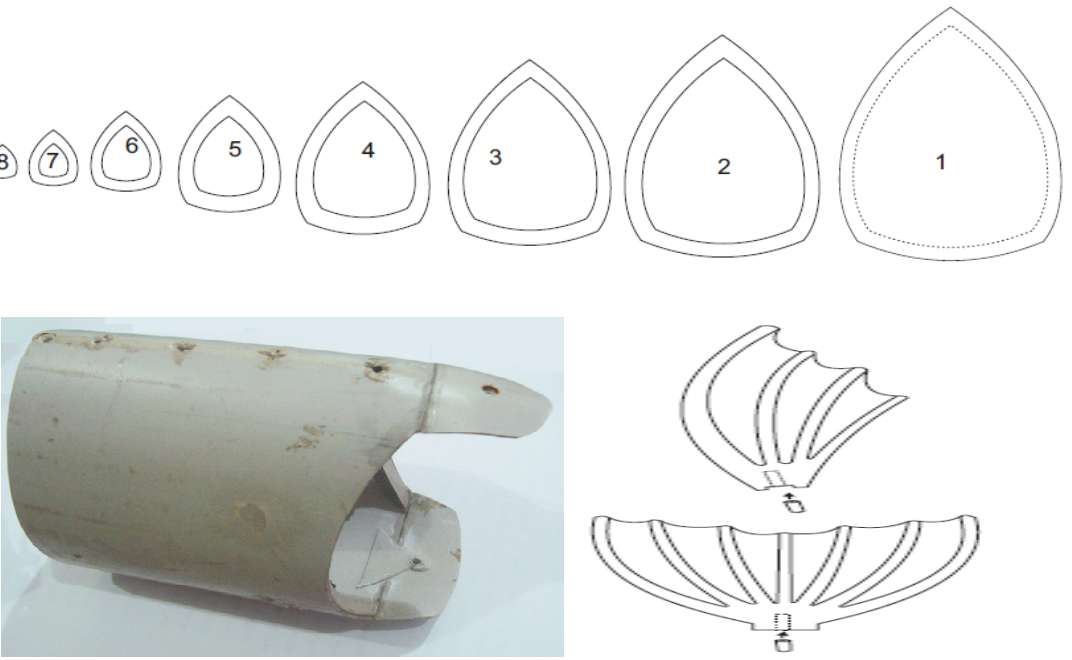

Figure 7. Parts of Robotic fish in blocks 
Computer Applications: An International Journal (CAIJ), Vol.3, No.1, May 2016

We have identified critical parameters such as size, shape which are included in the computational test process and supportive results have been listed for analysis purpose. The undulation motion has its own set of pros and cons, here we analyse several undulation fish models to maximize the swimming efficiency.

\section{CONClusion}

Construction of a robotic fish prototype is a challenging task because of the style of swimming adapted in it. In case of undulation motion where part of the body along with tail is involved hence using servomotors as an actuator to generate the flexible moving pattern becomes very easy as mentioned in the cases 2, 5,6,7,8 and 9. Using sensors such as gyroscope, accelerometer, pressure, proximity helps in producing perfect control over the movement of robot indicated in cases such as 3,5,7 and 9. More than $70 \%$ of robotic fish models use servomotor, as it is easy to control and compact in size and it is available in variety of models. Only case 3 studies about backward swimming using a flapping mechanism but its velocity is very low. In all the cases thrust for movement is generated using a harmonic motion of BCF is heavily involved as it serves as the base. So generating study movement of the tail having varied fin properties directly affects the performance which is indicated and listed in the table 2 . The proposed framework suggests fin properties in terms of size, shape, flexibility, speed and direction, to be considered while designing prototype models or even during simulation. To reduce the time involved are to study the characteristics of respective prototype.

\section{REFERENCES}

[1] Chao Zhou, Zhiqiang Cao, Zeng-Guang Hou and Shuo Wang., 2013."Backward swimming gaits for a carangiform robotic fish".Neural Computer \& Application.

[2] Donya Mohammadshahi, Aghil Yousefi-koma, Shahnaz Bahmanyar, Hassan Ghassemi and Hessam Maleki.,2014.”Design, Fabrication and Hydrodynamic Analysis of a Biomimetic Robot Fish".International Journal Of Mechanics.

[3] Fangfang Liu, Can-Jun Yang, and Kok-Meng Lee.,2010 Fellow,IEEE/ASME.”Hydrodynamic Modeling of an Undulating Fin for Robotic Fish Design".Advanced Intelligent MechatronicsMontréal, Canada, July 6-9.

[4] Guan, Zhenying, Gao, Weimin, Gu, Nong and Nahavandi, Saeid.,2010.3D "3D Hydrodynamic Analysis of a Biomimetic Robot Fish". International Conference Control, Automation, Robotics and Vision.

[5] Huosheng Hu, Jindong Liu, Ian Dukes and George Francis., 2006.”Design of 3D Swim Patterns for Autonomous Robotic Fish". International Conference on Intelligent Robots and Systems October 9 15.

[6] K. H. LOW.,2007."Locomotion simulation and system integration of robotic fish with modular undulating fin".School of Mechanical and Aerospace Engineering Nanyang Technological University, Singapore.

[7] Li Wen1, Jianhong Liang, Qi Shen, Lei Bao and Qia Zhang.,April 2010."Hydrodynamic Performance of an Undulatory Robot: Functional Roles of the Body and Caudal Fin Locomotion". International Journal of Advanced Robotic Systems.

[8] Mohsen Siahmansouri, Ahmad Ghanbari and Mir Masoud Seyyed Fakhrabadi., Oct 2011."Design, Implementation and Control of a Fish Robot with Undulating Fins".International Journal of Advanced Robotic Systems.

[9] Sanaz Bazaz Behbahani, Jianxun Wang, and Xiaobo Tan., 2013."A Dynamic Model for Robotic Fish with Flexible Pectoral Fins".IEEE/ASME International Conference on Advanced Intelligent Mechatronics (AIM) Wollongong,Australia, July 9-12. 
Computer Applications: An International Journal (CAIJ), Vol.3, No.1, May 2016

[10] S. Rajamohamed and P. Raviraj, September 2015.”Bio-Inspired Swimming Techniques for Robotic Fish using Flow and Pressure Sensing Mechanism (Computational Bio-Mimetic)". Indian Journal of Science and Technology, Vol 8(24), IPL0317.

[11] https://en.wikipedia.org

[12] https://commons.wikimedia.org/wiki/File:Filose_fish_robot_on_the_table.jpg

[13] https://www.google.co.in/search?q=robo+tuna+fishes+images 